\title{
Predicting Neointimal Hyperplasia in Stented Arteries Using Time- Dependant Computational Fluid Dynamics: A Review
}

\author{
Jonathan Murphy \\ Technological University Dublin, jonathan.murphy@tudublin.ie \\ Fergal Boyle \\ Technological University Dublin, fergal.boyle@tudublin.ie
}

Follow this and additional works at: https://arrow.tudublin.ie/engschmecart

Part of the Biomedical Engineering and Bioengineering Commons

\section{Recommended Citation}

Murphy, Jonathan and Boyle, Fergal, "Predicting Neointimal Hyperplasia in Stented Arteries Using TimeDependant Computational Fluid Dynamics: A Review" (2010). Articles. 20.

https://arrow.tudublin.ie/engschmecart/20

This Review is brought to you for free and open access by the School of Mechanical and Design Engineering at ARROW@TU Dublin. It has been accepted for inclusion in Articles by an authorized administrator of ARROW@TU Dublin. For more information, please contact arrow.admin@tudublin.ie, aisling.coyne@tudublin.ie, gerard.connolly@tudublin.ie.

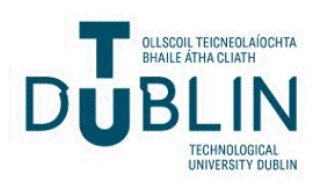




\title{
Predicting neointimal hyperplasia in stented arteries using time-dependant computational fluid dynamics: A review
}

\author{
Jonathan Murphy*, Fergal Boyle \\ Department of Mechanical Engineering, Dublin Institute of Technology, Ireland
}

\section{A R T I C L E I N F O}

Article history:

Received 3 September 2009

Accepted 8 February 2010

Keywords:

Coronary stent

Computational fluid dynamics

Restenosis

Wall shear stress

\begin{abstract}
A B S T R A C T
This paper reviews the recent literature regarding the time-dependant computational fluid dynamics (CFD) analyses of blood flow through implanted coronary stents. The in vivo processes which result in arterial restenosis are identified. The definition and range of the computationally predicted variables which are believed to stimulate the restenosis processes are evaluated. The reviewed literature is subdivided into effect-based in which the effects of altering the flow model are investigated and designbased in which different geometric stent configurations are compared. Finally, conclusions are made regarding the body of work reviewed and recommendations are provided for future work in this field.
\end{abstract}

(c) 2010 Elsevier Ltd. All rights reserved.

\section{Introduction}

\subsection{Coronary heart disease}

Coronary heart disease (CHD) is the single most common cause of death in Europe, accounting for 1.92 million deaths in 2008 [1]. CHD is a narrowing of the small arteries which supply blood containing oxygen and nutrients to the heart muscle and surrounding tissue. The most common form of CHD is atherosclerosis, a build up of "plaque" in one or more of the coronary arteries, which restricts blood flow.

\subsection{Percutaneous transluminal coronary angioplasty}

Traditionally, a coronary artery bypass graft (CABG) was the most popular procedure for the treatment of symptomatic atherosclerosis. This invasive procedure involves the opening of the chest and the grafting of a blood vessel to bypass the blockage. There is typically a two to three month patient recovery period following a CABG.

The first minimally invasive treatment of atherosclerosis was performed in 1977 by Gruentzig [2] and is known as percutaneous transluminal coronary angioplasty (PTCA). In this procedure an inflatable balloon is threaded to the site of the narrowed vessel on a catheter and then inflated and deflated several times, increasing the vessel size. Although this revolutionary procedure greatly reduced patient trauma, a re-blockage of the artery in a process known as restenosis is common with PTCA with incidence as high

\footnotetext{
* Corresponding author. Tel.: +35314023963.

E-mail addresses: jonathan.murphy@dit.ie,jmurphy_bst@hotmail.com (J. Murphy).
}

as $50 \%$ after six months [3-5]. Restenosis after PTCA most commonly takes the form of elastic recoil of the vessel wall and also vessel contraction known as negative remodelling. Elastic recoil and negative remodelling were virtually eliminated by the introduction of stents in the early 1990s.

\subsection{Coronary stents}

A coronary stent is an artificial support device used in the coronary artery to keep the vessel open. Modern stents are usually mounted on balloon catheters in a "crimped" or collapsed state. When the balloon is inflated during the stenting procedure, the stent expands and pushes itself against the inner wall of the coronary artery. This acts as a scaffold to hold the artery open; the balloon is then deflated and removed. By forming a rigid support, the stent can prevent restenosis due to elastic recoil and negative remodelling.

Unfortunately, the stented artery is also susceptible to restenosis. Angiographic restenosis is commonly defined as a loss of greater than $50 \%$ of the initial arterial diameter gained from the stenting procedure [6]. Bare metal stents (BMS) still experienced restenosis (typically at six months) in about $25 \%$ of cases, necessitating a repeat procedure $[7,8]$. Stenting does not eliminate restenosis but merely lends itself to a different mechanism than PTCA. The mechanism of restenosis after stenting has four key processes described below.

\subsection{Restenosis}

Following a stent implantation, the stented segment of the artery can be re-narrowed by four key processes: thrombus formation, arterial inflammation, neointimal hyperplasia $(\mathrm{NH})$ 
and remodelling. If the re-narrowing exceeds the threshold described above in Section 1.3, a restenosis of that artery has occurred.

Thrombus formation: Stenting causes arterial injury by damaging the endothelial cells which line the inner artery wall, plaque compression and in extreme cases, dissection of the inner arterial wall. The damaged parts of the artery attract blood-borne platelets to the source of arterial injury around the stent struts. The platelets are transported to the injured site via the blood flow where they adhere to the damaged cells and release chemical attractants for other platelets. A stringy protein called fibrin then forms around the platelets to bind them together into a thrombus. The formation of thrombus begins immediately after stent implantation and is the dominant physiological response in the first seven days after implantation.

Arterial inflammation: The immune system reacts to the presence of the stent with what is known as an inflammatory response. This involves white blood cells infiltrating the vessel wall around the site of the injury within the first $24 \mathrm{~h}$ post procedure. The white blood cells are chemically attracted to the site of arterial injury but must be transported there via the blood flow in a similar fashion to platelets.

Neointimal hyperplasia: Within weeks of stent implantation, the growth of new tissue occurs rapidly inside the artery around the implanted stent. This process is known as NH. Smooth muscle cells which normally reside in the middle layer of the artery migrate inwards towards the stent where they proliferate and form the bulk of the new tissue that narrows the artery. The migration and proliferation of smooth muscle cells is triggered by chemical signals which have a variety of sources in the stented artery including: injured endothelial cells, dysfunctional endothelial cells, activated platelets at the site of the arterial injury, white blood cells which have infiltrated the endothelial cells, and healthy smooth muscle cells which have migrated to the site of the injury.

Remodelling: From approximately four weeks after stenting, collagen deposits in the outer layers of the artery lead to arterial shrinkage known as negative remodelling. This process increases pressure on the stent and can squeeze some of the artery wall through the inter-strut space from without.

Mechanism: The mechanism of restenosis after stenting consists of the four processes described above in chronological order. These processes are triggered and maintained by stimuli from the stenting procedure. Broadly speaking, the predominant stimuli are the presence of the stent, the injury incurred from the stenting procedure and the abnormal haemodynamics due to the presence of the stent.

The growth of new tissue from the $\mathrm{NH}$ process is predominantly what re-blocks the artery, and if kept minimal the stenting procedure is likely to be successful. However, if the tissue growth is excessive and the artery cannot accommodate the new tissue without losing patency, a repeat procedure will be necessary.

\subsection{Computational modelling}

Obtaining a full comprehension of the mechanism of arterial restenosis after stenting is extremely important for the future of minimally invasive cardiology. If the stimuli of the four above processes are identified, they can be reduced or eliminated by way of stent design and stenting procedure. The fact that restenosis occurs in vivo and in vessels of approximately $3 \mathrm{~mm}$ in diameter makes it extremely difficult to obtain experimental data to quantify these process stimuli. However, modern computational models can accurately simulate the environment of the stented artery, and as such are currently the best available method to investigate the stimuli of the processes which can cause restenosis of a stented artery.

One type of computational modelling is called finite element analysis and endeavours to predict the stresses induced in the artery wall from the stenting procedure. This can provide information as to the extent of possible arterial injury with a particular procedure or stent design. Computer modelling has shown that implanted stents that produce greater volumes of arterial tissue with maximum principle stress above $4 \mathrm{MPa}$ have higher restenosis rates [9]. This suggests that maximum principle stress above this threshold is a stimulus for one or more the processes which cause restenosis.

Computational fluid dynamics (CFD) has also focused on the local haemodynamics of the stented artery to identify stimuli for restenosis. Models are developed to predict variables such as wall shear stress (WSS) and wall shear stress gradient (WSSG). Oscillatory shear stress over the cardiac cycle can be predicted with the oscillatory shear index (OSI). Recirculation zones with separation and attachment points are identified with the flow separation parameter (FSP). Specific ranges of these variables on the walls of the stented artery have been shown to be stimuli for the processes which can cause restenosis and are discussed in Section 3.

Increased computational power has enhanced the physiological realism of these models in recent years. CFD models now tend to be fully three-dimensional (3D) and include important features such as non-Newtonian blood flow, vessel curvature, tissue prolapse between stent struts, realistic stent design and time-dependant flow. There has now been almost a decade of this high-end CFD modelling of the stented artery to provide insight into the mechanism of restenosis. This review focuses on physiologically realistic time-dependant CFD models of stented arteries. These models each provide important data which is reviewed for the first time in this article to determine what level of insight they can collectively bring to the mechanism of restenosis.

The following section contains the mathematical descriptions and discusses the relevance of the most important variables to indicate sites of excessive $\mathrm{NH}$ which is the primary process in the mechanism of restenosis. The publications are reviewed in Section 3 and conclusions and recommendations discussed in the final section.

\section{Variables to predict locations of neointimal hyperplasia}

\subsection{Introduction}

The primary process which leads to in-stent restenosis is $\mathrm{NH}$, which is the excessive growth of tissue inside the stented segment. As discussed earlier in Section 1.4, this growth is triggered by chemical signals from sources that include endothelial cell damage and dysfunction, platelet adhesion, white blood cell infiltration and SMC signalling. Abnormal haemodynamics near the stent is an $\mathrm{NH}$ stimulus through the production of abnormal stresses on the endothelial cells and also through the increased advection of platelets and white blood cells to the artery wall.

Thus, haemodynamic variables have been formulated to identify sites in the artery where $\mathrm{NH}$ is more likely due to these factors. The purpose of this section is to discuss how each of the most widely used of these variables directly contributes to the process of $\mathrm{NH}$. The mathematical descriptions of the variables are also provided. 


\subsection{Wall shear stress}

The distribution of WSS in arterial flows has been the subject of considerable research in the past decade due to its association with vascular disease. Endothelial cells subjected to elevated levels of WSS $>1 \mathrm{~N} / \mathrm{m}^{2}$ tend to elongate and align in the direction of flow, whereas those experiencing low or oscillatory WSS $<0.5$ $\mathrm{N} / \mathrm{m}^{2}$ are circular in shape and have no preferred alignment pattern [10]. These circular cells, coupled with the blood stagnation usually seen in areas of low WSS leads to increased uptake of blood bourne particles to the artery wall as a result of increased residence time and increased permeability of the endothelial layer. It has been demonstrated that tissue growth in a stented artery was prominent at the sites of low WSS [11].

In mathematical terms, the scalar dot product of the unit normal vector $\vec{n}$ to a surface and the fluid viscous stress tensor $\overrightarrow{\vec{\tau}}_{i j}$ yields a vector whose magnitude is equal to the viscous stress on the surface, and whose direction is the direction of the viscous stress acting on the surface. This is called the WSS vector and is written

$\vec{\tau}_{W}=\vec{n} \cdot \vec{\tau}_{i j}$

For time-dependant flows, one of the most commonly predicted variables is the time-averaged WSS (TAWSS) defined as

TAWSS $=\frac{1}{T} \int_{0}^{T}\left|\vec{\tau}_{w}\right| d t$

where $T$ is the duration of one cardiac cycle and $d t$ is a small increment of time.

\subsection{Wall shear stress gradient}

A large WSSG acting on the artery wall could increase the permeability of endothelial cells by forcing them out of alignment with each other due to the different magnitudes of WSS. Sites that are susceptible to $\mathrm{NH}$ have been correlated with sites where the WSSG has been predicted to exceed $200 \mathrm{~N} / \mathrm{m}^{3}$ in an end to side anastomosis model [12,13] and a rabbit iliac model [11].

Contact with the stent struts and balloon damages and denudes the endothelial cells during implantation. It is important that a new layer of endothelial cells grows in these denuded locations to form a barrier between the blood and exposed subendothelial layer. High WSSG is known to affect this process as endothelial cells have been shown to migrate downstream of an area where the WSSG was approximately $5000 \mathrm{~N} / \mathrm{m}^{3}$ [14].

To mathematically describe the WSSG, first define three mutually orthogonal axes of a local coordinate system as $m$, the WSS direction tangential to the endothelial surface, $n$, tangential to the endothelial surface and normal to $m$, and $l$, the endothelial surface normal direction. This new coordinate system can then be used to get the pertinent components of the WSSG tensor. A scalar combination of these components is taken as the WSSG and is calculated as

WSSG $=\left[\left(\frac{\partial \tau_{w, m}}{\partial m}\right)^{2}+\left(\frac{\partial \tau_{w, n}}{\partial n}\right)^{2}\right]^{1 / 2}$

where $\tau_{w, m}$ and $\tau_{w, n}$ are the components of the WSS vector in the $m$ and $n$ directions respectively. For pulsatile flow, time-averaged WSSG (TAWSSG) is written

TAWSSG $=\frac{1}{T} \int_{0}^{T}|\overrightarrow{\mathrm{WSSG}}| d t$

where the symbols have their usual meaning.

\subsection{Oscillatory shear index}

The oscillatory shear index (OSI) was originally proposed to identify regions of low oscillatory WSS in carotid arteries [15]. Regions of high OSI have been shown to be at greater risk of arterial narrowing from atherosclerosis [16]. Endothelial permeability to blood borne particles have also shown to be increased with higher OSI [17]. Oscillatory WSS has also lead to increased production of the gene endothelin $1 \mathrm{mRNA}$ which increases cell proliferation [18]. It is therefore likely that sites of high OSI will be at an increased risk of $\mathrm{NH}$ in the stented artery.

Although some regions of the coronary tree such as the left anterior descending may exhibit some natural flow reversal over the cardiac cycle [19], the presence of a stent may greatly enhance the amount of oscillatory WSS in certain parts of the artery. OSI values range between 0 when there is no oscillatory WSS to 0.5 when there is maximum oscillatory WSS. The OSI is mathematically described as

$\mathrm{OSI}=\frac{1}{2}\left(1-\frac{\left|\int_{0}^{T} \vec{\tau}_{w} d t\right|}{\int_{0}^{T}\left|\vec{\tau}_{w}\right| d t}\right)$

The OSI always returns a positive value which limits the directional information which can be obtained about the WSS over the cardiac cycle. Rajamohan et al. [20] proposed the modified oscillatory shear index (MOSI) written

$\operatorname{MOSI}=\frac{\int_{0}^{T} \vec{\tau}_{w} d t}{\int_{0}^{T}\left|\vec{\tau}_{w}\right| d t}$

where removing the modulus from the numerator returns the direction of the TAWSS vector over the cardiac cycle.

\subsection{Flow separation parameter}

The flow separation parameter (FSP) quantifies the fraction of time with respect to one cardiac cycle that flow at some point on the arterial wall is separated from the mainstream flow (i.e. stagnation or recirculation). In vitro testing has demonstrated that dye becomes trapped in regions where stent strut spacing is small; CFD analysis subsequently showed that the FSP is large in these regions [21]. This is significant as platelets, lipids and white blood cells may have large residence times in areas where the FSP is high in the stented artery which could lead to increased $\mathrm{NH}$. The FSP is written

$\varphi=\frac{T_{s}}{T}$

where $T_{S}$ is the amount of time that the flow is separated and $T$ is the duration of one cardiac cycle. Flow separation is defined by $\mathrm{He}$ et al. as occurring when the angle between the WSS vector and the mean flow direction is greater than $90^{\circ}$ [22]. The FSP has also been modified for low flow conditions to account for the natural shear stress oscillation as follows:

$\varphi=\frac{T_{P} \varphi_{P o s}+T_{N} \varphi_{N e g}}{T}$

where $\varphi_{\text {Pos }}$ is the separation parameter during the time of forward mainstream flow $T_{P}, \varphi_{\text {Neg }}$ is the separation parameter during the time of reverse mainstream flow $T_{N}$, and $T$ is the total time of the flow cycle $\left(=T_{P}+T_{N}\right)$. 


\section{Time-dependant computational fluid dynamics models}

\subsection{Introduction}

Restenosis has been shown to vary in rate from one stent design to another [23]. $\mathrm{NH}$ has also been shown to be more prominent in certain locations in the stented artery [11,24-27]. The ultimate goal of these CFD analyses is to give reasons why some stents or stent locations are more $\mathrm{NH}$ prone than others. Specific value ranges of the variables discussed in Section 2 are believed to encourage $\mathrm{NH}$. Therefore, investigators predict these variables and quantitatively assess locations in the stented artery that fall inside the "NH range". They may also qualitatively identify predicted features of the flow such as recirculation zones, separation and reattachment points to identify locations where NH may be accelerated.

The research in this field can be divided into two broad categories; the first is effect-based research which examines different scenarios in the stented artery. Two or more similar models with a well defined difference are compared quantitatively, qualitatively or both. Examples of this include comparing straight and curved arteries, different stent sizing and Newtonian versus non-Newtonian blood flow. The second category is designbased research which investigates the geometric configuration of the stent design itself. All of the work reviewed in this section is summarised in Table 1.

\subsection{Effect-based research}

LaDisa et al. hypothesised that axial stent strut angle influences WSS and WSSG in the stented artery [28]. Their models consisted of stents deployed at 1.2 to 1 stent to artery ratio at lengths of $16 \mathrm{~mm}$ (ideal) and progressively foreshortened 14 and $12 \mathrm{~mm}$ as shown in Fig. 1A. Thresholds for low WSS and high WSSG were set at $0.5 \mathrm{~N} / \mathrm{m}^{2}$ and $200 \mathrm{~N} / \mathrm{m}^{3}$ respectively at mean blood flow velocity. The main findings were that although the total area exposed to low WSS reduces with progressive foreshortening with 117,111 and $96.8 \mathrm{~mm}^{2}$, when normalised by the stented area there is an increase in normalised area exposed to low WSS with $0.71,0.77$ and 0.78 for the 16,14 and $12 \mathrm{~mm}$ lengths respectively. There was no significant difference in area exposed to high WSSG; however the maximum WSSG increased with progressive foreshortening with values of 248, 293 and $395 \mathrm{~N} / \mathrm{m}^{3}$ for the 16,14 and $12 \mathrm{~mm}$ lengths respectively.
Another finding was that under mean flow conditions the percentage of intrastrut area exposed to low WSS was greatest in the proximal area regardless of stent length or strut orientation.

This study demonstrates that progressive strut misalignment with the flow direction increases normalised arterial wall area exposed to low WSS and elevates WSSG. The intuitive observation from this result is that stent struts should be aligned with the flow to reduce these effects.

The geometric model in Fig. 1B was used by Rajamohan et al. [20] and Banerjee et al. [29] in a joint study to compare the effect of developing versus developed flow in a stented coronary artery. Developing flow was simulated by imposing a transient plug flow at the inlet of the CFD model and was representative of flow through a stent deployed at the origin of a branched artery [20]. Developed flow was simulated with a transient parabolic velocity profile at the inlet [29]. This model represented flow through a stent implanted at a downstream region of a coronary artery.

The velocity profiles near the entrance and exit are shown in Figs. 2A and B respectively. The profiles are given at four different times for developed flow and at $t=2.0 \mathrm{~s}$ for developing flow which is the time of peak inlet velocity. For developed flow, a near parabolic velocity profile is observed with the peak velocity at the centre for all flow rates. For developing flow the peak velocity occurs close to the artery wall, near the entrance and exit. There is an $83 \%$ and $37 \%$ increase in the near wall velocity gradient at the inlet and outlet respectively from developed to developing hyperaemic flow of $200 \mathrm{ml} / \mathrm{min}$ at time $=2.0 \mathrm{~s}$. The higher near wall velocity gradient at the inlet for developing flow accounts for the higher WSS magnitude of $53 \mathrm{~N} / \mathrm{m}^{2}$ predicted on the first strut intersection compared with the magnitude of $29 \mathrm{~N} / \mathrm{m}^{2}$ on the first strut intersection with developed flow.

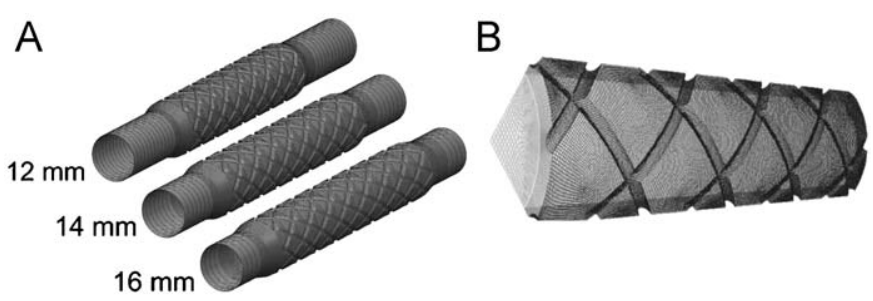

Fig. 1. (A) Three models of a stented coronary artery which are different lengths due to foreshortening from LaDisa et al. [28]. (B) Model of a stented coronary artery from Rajamohan et al. [20].

Table 1

A list of the publications that are reviewed in this paper.

\begin{tabular}{|c|c|c|c|c|c|c|c|}
\hline Author & Year & Reynolds no. & Wormersley no. & Dynamic viscosity (Ns/m²) & Timestep (ms) & Period (s) & Mesh nodes (n), elements (e) \\
\hline Chen [38] & 2009 & - & - & 0.0040 & - & - & - \\
\hline Duraiswamy [41] & 2009 & 130 (avg.) & 2.80 & 0.0040 & 8.57 & 0.86 & 640,008 e (max.) \\
\hline Balossino [44] & 2008 & 105 (avg.) & 2.87 & 0.0037 & - & 0.52 & $160,000 \mathrm{n}$ \\
\hline Duraiswamy [43] & 2008 & 130 (avg.) & 2.80 & 0.0040 & 8.57 & 0.86 & 640,008 e (max.) \\
\hline Banerjee [29] & 2007 & 800 (peak) & 2.32 & Non-Newtonian & $0.1-1.0$ & 0.80 & 650,000 e \\
\hline Faik [30] & 2007 & 240 (avg.) & 2.80 & - & - & 0.80 & $192,000 \mathrm{e}$ \\
\hline LaDisa [37] & 2006 & 105 (avg.) & 2.91 & 0.0037 & 8.00 & 0.54 & $500,000 \mathrm{n}$ \\
\hline Rajamohan [20] & 2006 & 800 (peak) & 2.32 & Non-Newtonian & $0.1-1.0$ & 0.80 & $650,000 \mathrm{e}$ \\
\hline He [22] & 2005 & $50-240$ & 5.00 & 0.0040 & 8.57 & 0.86 & 279,083 e \\
\hline LaDisa [28] & 2005 & 105 (avg.) & 2.91 & 0.0037 & 8.00 & 0.54 & $250,000 \mathrm{n}$ \\
\hline LaDisa [32] & 2005 & 105 (avg.) & 2.91 & 0.0037 & 8.00 & 0.54 & $250,000 \mathrm{n}$ \\
\hline LaDisa [11] & 2005 & 105 (avg.) & 2.91 & 0.0037 & 8.00 & 0.54 & - \\
\hline Seo [35] & 2004 & 200 (avg.) & 2.80 & Non-Newtonian & - & - & $99,492 n$ \\
\hline Frank [40] & 2002 & - & - & 0.0035 & 7.81 & - & - \\
\hline Berry [21] & 2000 & - & - & - & - & - & - \\
\hline
\end{tabular}

These publications all involve computational fluid dynamics modelling of time-dependant blood flow through a stented coronary artery. 

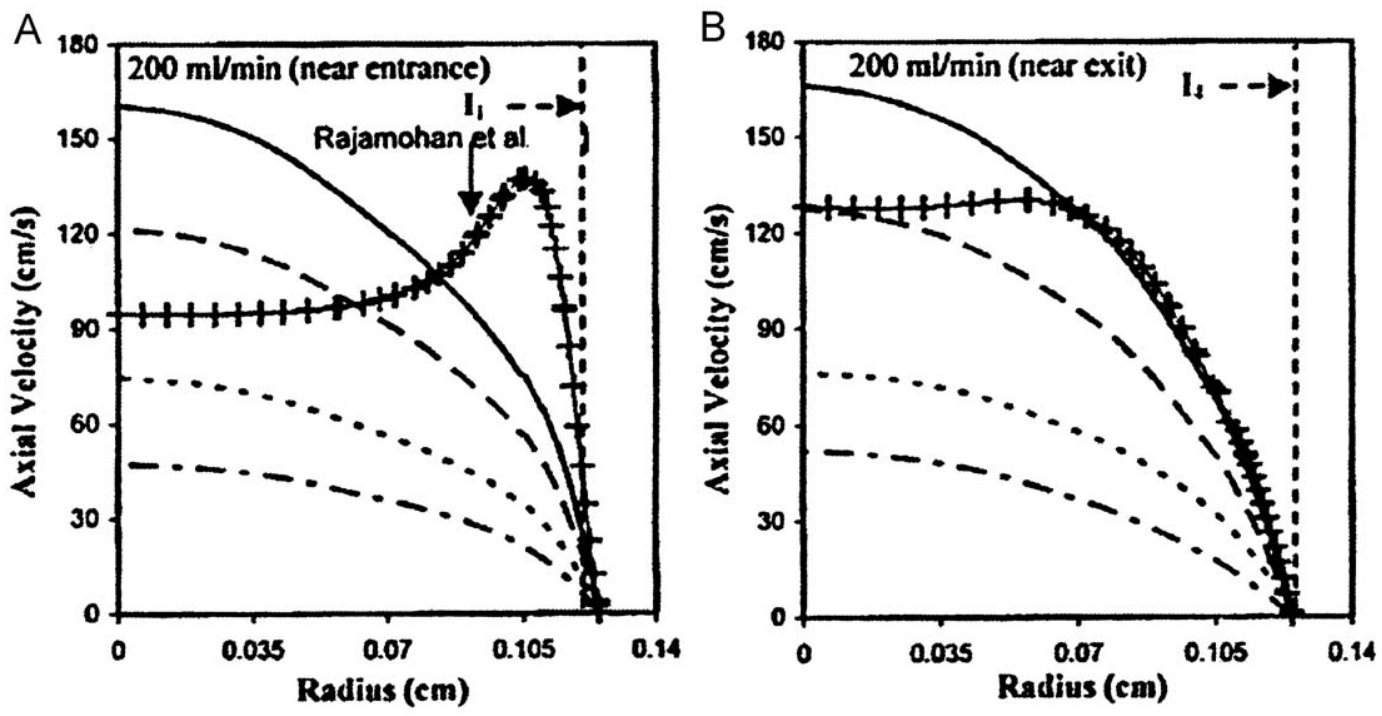

$$
\begin{gathered}
\cdots \cdots \cdots \cdot t=1.85 \mathrm{~s}-t=2.00 \mathrm{~s}----t=2.20 \mathrm{~s} \\
-1-1-1-t=2.00 \mathrm{~s} \quad-\cdots-t=2.30 \mathrm{~s}
\end{gathered}
$$

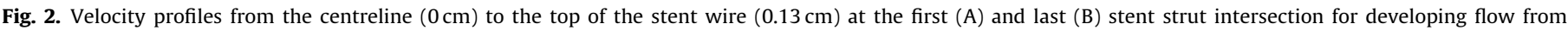
Rajamohan et al. [20] and developed flow from Banerjee et al. [29].

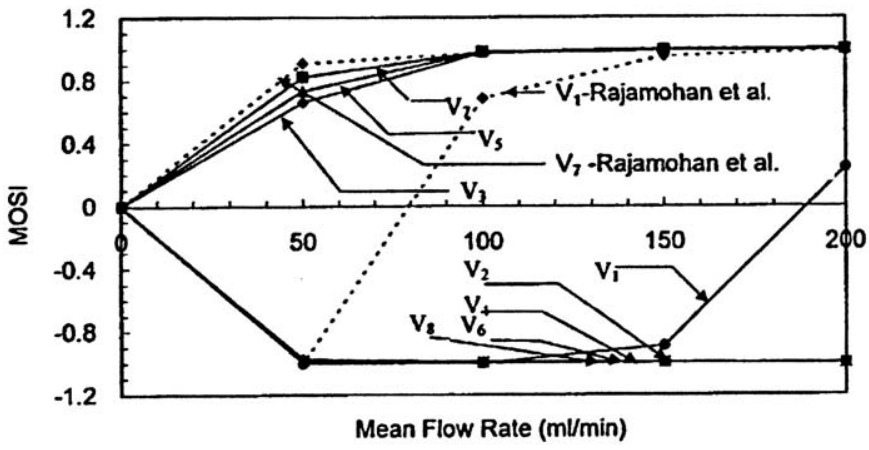

Fig. 3. The modified oscillatory shear index (MOSI) for vertices V1-V8 from the inlet to outlet respectively for flow rates 50,100, 150 and $200 \mathrm{ml} / \mathrm{min}$ for developing flow from Rajamohan et al. [20]. Vertices V1 and V7 are also shown for developed flow from Banerjee et al. [29].

To further analyse the flow the MOSI is plotted upstream and downstream of the four strut intersections shown in Fig. 1B. These vertices are labelled V1-V8 from inlet to outlet respectively. For developed flow, MOSI values of nearly +1 and -1 are observed at the upstream and downstream of each strut intersection, respectively for all flow rates as shown in Fig. 3. This demonstrates that there is negative WSS at the downstream of each intersection (V2, V4, V6 and V8) and positive WSS at the upstream of each strut intersection (V3, V5 and V7) except near the entrance, where there is negative WSS for 50,100 and $150 \mathrm{ml} / \mathrm{min}$ flow rates. These negative MOSI values signify recirculation zones downstream of each strut intersection for all flow rates and upstream of the first strut intersection for $50 \mathrm{ml} /$ min with developing flow and with 50,100 and $150 \mathrm{ml} / \mathrm{min}$ for developed flow.

These studies have also shown that when compared with developed flow, maximum recirculation length and height downstream of strut intersections for developing flow are 100\% and 50\% higher respectively. This study highlights the significant impact of a stents location in the artery on the local haemodynamic environment.

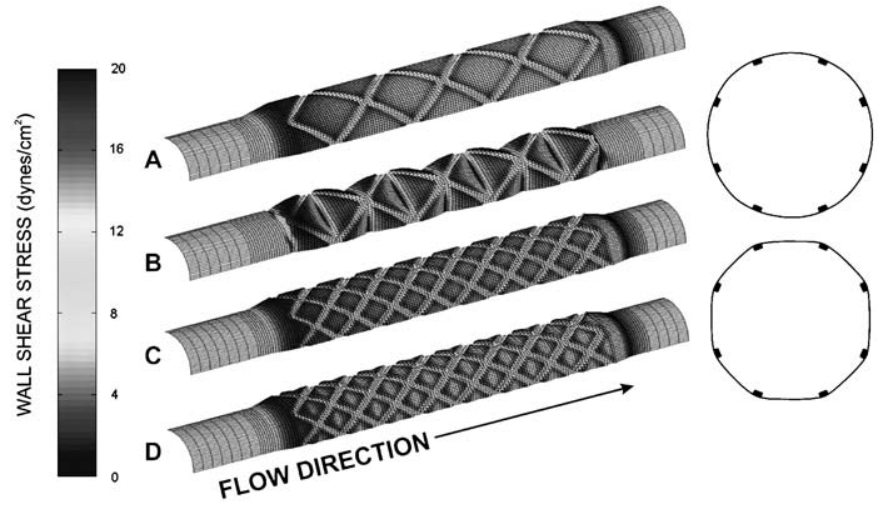

Fig. 4. Models of a stented artery with circular and deformed arterial tissue around the stent for four and eight struts from LaDisa et al. [32].

Many investigators use a simplified circular arterial cross section when modelling the arterial wall [20,28-31]. LaDisa et al. have examined the effect of circumferential vascular deformation on a CFD model of the stented artery [32]. The models with circumferential vascular deformation were created simply by joining the vertices of the stent struts to make a polygonal shape as shown in Fig. 4. The major finding was that the maximum WSSG was $221 \mathrm{~N} / \mathrm{m}^{3}$ with a circular cross section and $706 \mathrm{~N} / \mathrm{m}^{3}$ with a polygonal cross section for the stent with four struts. The area exposed to high WSSG $>200 \mathrm{~N} / \mathrm{m}^{3}$ was 76.8 and $100 \mathrm{~mm}^{2}$ for four struts and 76.4 and $89.2 \mathrm{~mm}^{2}$ for eight struts for circular and polygonal cross section respectively. The area exposed to low WSS $<0.5 \mathrm{~N} / \mathrm{m}^{2}$ was 419.5 and $437.2 \mathrm{~mm}^{2}$ for circular and polygonal respectively with four struts and 126.0 and $117.4 \mathrm{~mm}^{2}$ for circular and polygonal respectively with eight struts.

The results demonstrate that when vascular deformation is taken into consideration, having fewer struts leads to increased areas of low WSS and elevated WSSG. From a modelling perspective, these results show that simplifying the arterial cross section to a circular shape can introduce significant error in the results, particularly with regard to WSSG. 
The majority of the coronary arteries have some degree of curvature. Arteriosclerotic lesions and tissue growth are more prominent on the inner or myocardial curve of the artery $[27,33]$. It has been demonstrated that the velocity profile tends to skew to the pericardial surface in curved arteries [34,35]. Wentzel et al. demonstrated that implantation of a stent may cause straightening of the coronary artery segment where the stent is deployed [36]. This straightening of the artery causes an increase in curvature of over $100 \%$ at the entrance and exit of the stented region. LaDisa has attempted to quantify this effect on the WSS [37]. Two models were created and are shown in Fig. 5, an artery stented with a flexible stent that conforms to the $20.3 \mathrm{~mm}$ radius of curvature of the artery and another stented with an inflexible

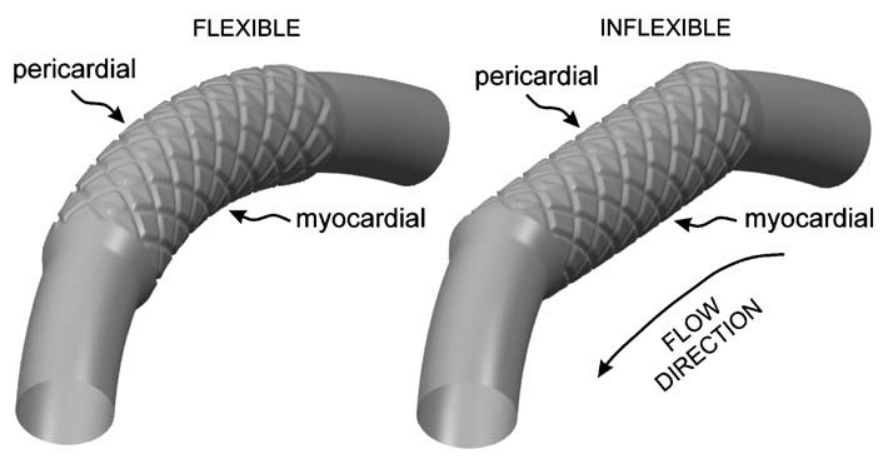

Fig. 5. "Flexible" and "inflexible" models of a stented artery from LaDisa et al. [37].

\section{Table 2}

Values of time-averaged wall shear stress in the centre of the first proximal and last distal diamond on the pericardial and myocardial surfaces for the "flexible" and "inflexible" models of a stented coronary artery from LaDisa et al. [37].

\begin{tabular}{|c|c|c|c|c|}
\hline \multirow{2}{*}{$\begin{array}{l}\text { Time-averaged } \\
\text { wall shear stress }\left[\mathrm{N} / \mathrm{m}^{2}\right]\end{array}$} & \multicolumn{2}{|l|}{ Proximal } & \multicolumn{2}{|l|}{ Distal } \\
\hline & Pericardial & Myocardial & Pericardial & Myocardial \\
\hline Flexible & 0.89 & 0.49 & 1.15 & 0.89 \\
\hline Inflexible & 1.17 & 0.43 & 0.83 & 1.26 \\
\hline
\end{tabular}

stent which straightens the artery similar to that reported by Wentzel et al. [36].

The total area exposed to low WSS $<0.5 \mathrm{~N} / \mathrm{m}^{2}$ was similar for the two models with 29.0 and $99.1 \mathrm{~mm}^{2}$ for the flexible stent at peak and mean flow respectively and 24.4 and $103.7 \mathrm{~mm}^{2}$ for the inflexible stent at peak and mean flow respectively.

The most interesting finding from this study was the timeaveraged WSS values in the centre of the first proximal and last distal diamond along the pericardial and myocardial luminal surfaces presented in Table 2. Both models show very low timeaveraged WSS on the myocardial surface at the proximal end. The inflexible stent has high values of time-averaged WSS on the proximal pericardial surface and the distal myocardial surface due to the reorientation of velocity profile as blood enters and leaves the region, respectively. The flexible stent allowed gradual transition from artery to stent and hence the velocity profile maintained its modest skewing toward the pericardial surface resulting in higher shear stress values on that surface along the length of the stent.

Previous work has shown that for a straight vessel implanted with a similar stent and conditions the time-averaged WSS has a value of $0.83 \mathrm{~N} / \mathrm{m}^{2}$ along the entire length of the stent [28]. The lower WSS values predicted on the myocardial surface and presented in Table 2, may account for the higher tissue growth in this region, particularly in the proximal region of the stent where the WSS is low regardless of stent flexibility.

Chen et al. have examined the effect of stent undersizing on endothelial WSS and WSSG, as well as OSI [38]. Three CFD models were created with stent undersizing of $5 \%, 10 \%$ and $20 \%$. As shown in Fig. 6, the presence of the stent struts decreases the WSS and increases the WSSG along the arterial wall with the $5 \%$ undersized stent. The presence of the stent wires becomes less significant with the $10 \%$ undersized case as the WSS and WSSG get closer to the non-stented values. This trend is continued with the $20 \%$ undersized case with the WSS and WSSG approaching the non-stented value further (not shown).

The results also include von Mises stress distribution in the arterial wall for $10 \%$ and $20 \%$ oversized cases, but does not have CFD results for the oversized cases. Whilst the results show that undersizing the stent could increase the WSS and reduce the
Axial WSS Profile
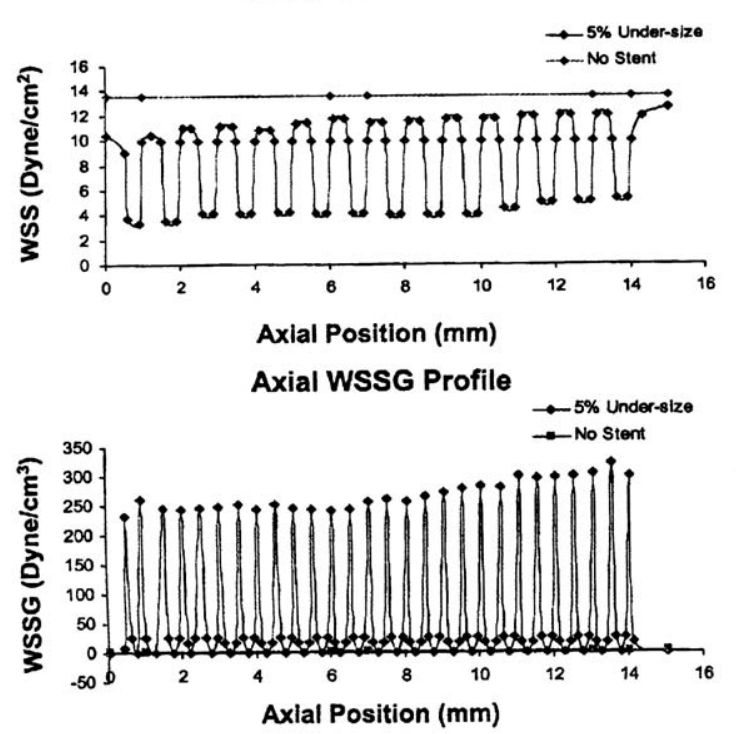

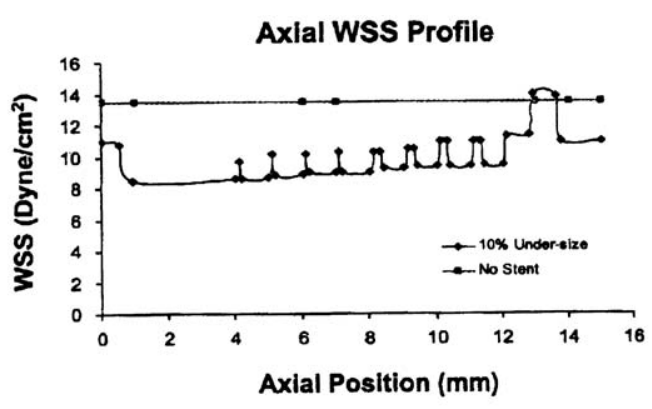

Axial WSSg Profile

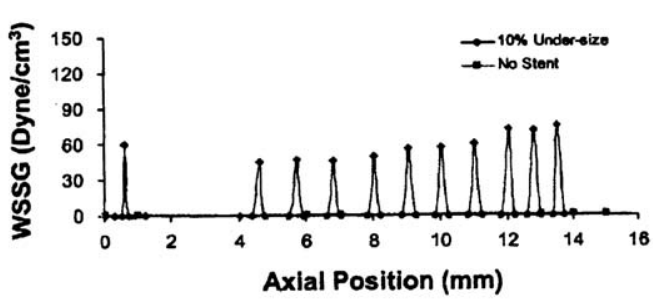

Fig. 6. The effects of $5 \%$ and $10 \%$ stent undersizing on the axial wall shear stress and wall shear stress gradient from Chen et al. [38]. 
WSSG, in practice stent oversizing to ensure maximum patency is more common [39].

Seo et al. created models to investigate flow disturbances in 2D straight and curved vessels with Newtonian and non-Newtonian flow [35]. Their main finding with time-dependant flow is that regions of flow disturbance periodically increase and decrease in size. The primary impact of the non-Newtonian properties of the blood is to reduce the size of the flow separation downstream of the stent by approximately $8 \%$.

Faik et al. have conducted time-dependant 3D simulations of a stented artery to study the characteristics of blood flow and shear rate [30]. The results show significant secondary flow in an annulus region near the artery wall as well as low shear rates on the artery wall near the struts and high shear rates on the tips of the struts.

\subsection{Design-based research}

The second type of research in this field is concerned with how the design of the stent impacts on the near-wall haemodynamics. The near-strut region of the artery wall is usually denuded of most endothelial cells during the stenting procedure and it is possible that the major influence of the blood flow on new tissue growth is through transport of particles to the artery wall. The inter-strut region is likely to retain most of the WSS sensitive endothelial cells during stenting. It is therefore important to quantify flow separation and WSS in the inter-strut region, as both can influence tissue growth through $\mathrm{NH}$.

He et al. have conducted a parametric comparison of strut design patterns illustrated in Fig. 7 [22]. The purpose of the study was to identify the effect of strut design on WSS and on the FSP in the inter-strut region. Blood was modelled as a homogeneous Newtonian incompressible fluid. The model had rigid wall boundaries and a sinusoidal input velocity. A significant finding was that within the narrow band of model (b) the mean axial WSS was very low at approximately $0.2 \mathrm{~N} / \mathrm{m}^{2}$, and the mean traverse WSS was approximately $30 \%$ higher than that of model (a).
Increasing the axial distance between the struts, $h$, to $3.6 \mathrm{~mm}$ increased the degree to which axial WSS was restored between the struts in model (c) and reduced the traverse WSS by $\sim 40 \%$. Increasing the axial strut length, $f$, did not significantly increase axial or decrease traverse WSS.

One of the most significant recommendations of this study was that the longitudinal distance between adjacent rows of struts should be maximised to restore WSS values between the struts. This has the effect of decreasing the FSP between the struts as shown in Fig. 8.

Frank et al. [40] conducted an in vitro platelet adhesion experiment in conjunction with a 2D CFD analysis to determine the effect of stent strut spacing on WSS, the FSP and platelet deposition. The lowest platelet deposition occurred at the shortest spacing of $2.5 \mathrm{H}(2.5 \times$ strut height $)$ with approximately double the platelet deposition at strut spacing of 4 and $7 \mathrm{H}$. The FSP was one everywhere between the two struts for the smallest spacing and had a value of zero for the majority of the space between the struts for the largest spacing. The WSS was only restored between the two struts for the largest strut spacing. As the spacing increased, there was flow reattachment between the struts which reduced the FSP. However, this reattachment transported platelets into the region between the two struts. This is an undesirable result as platelet accumulation around the stent struts is likely to increase the volume of $\mathrm{NH}$. On the other hand, the endothelial cells are more likely to be functional and prevent $\mathrm{NH}$ with the larger spacing since the WSS has been restored. These results are consistent with the conclusions of Berry et al. that flow reattachment occurs after a strut spacing of six diameters for a circular strut [21].

Duraiswamy et al. extended this work to four commercially available stents [41]. They created models of single units of the Wallstent (Boston-Scientific Corp., Natick, MA), Bx-Velocity stent (Cordis Corp., Miami, FL), Aurora stent (Medtronic, Inc., Minneapolis, MN) and the NIR stent (Boston-Scientific Corp., Natick, MA). The stents were modelled as single unit cells on a flat rigid surface and the computational domain had a sinusoidal input velocity with a frequency of $1.1 \mathrm{~Hz}$. The main results are listed in Table 3 a

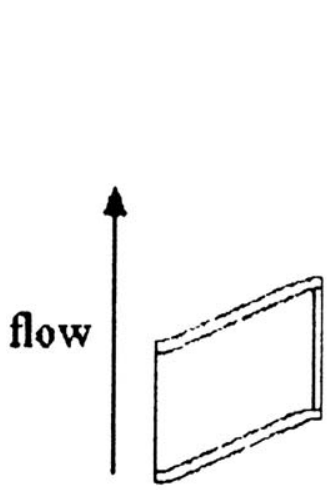

$h=1.8 \mathrm{~mm}$
$f=0.9 \mathrm{~mm}$
$r=0.45 \mathrm{~mm}$ b

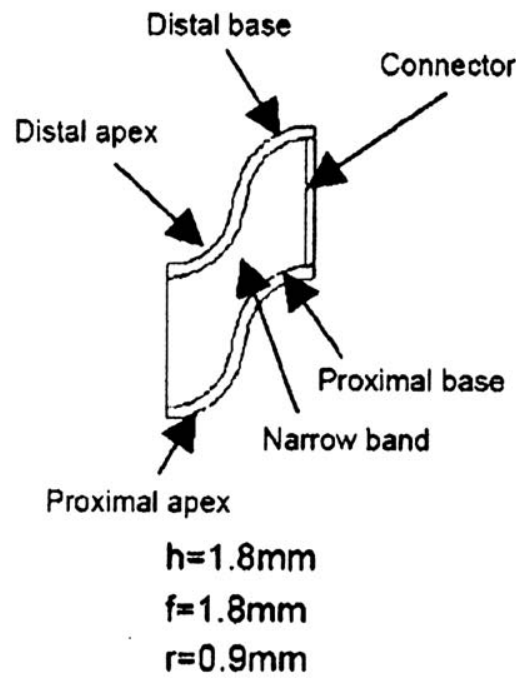

C
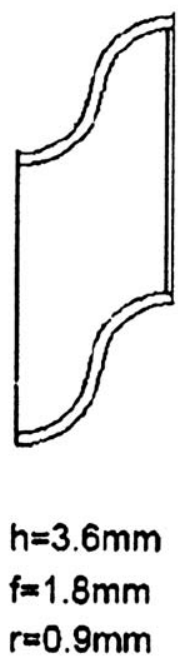

d

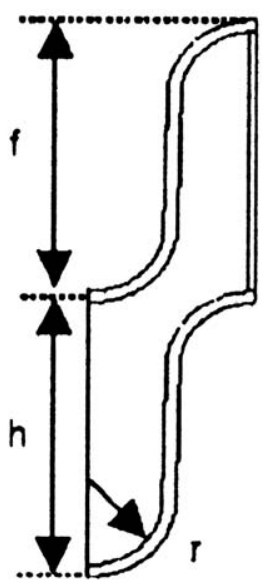

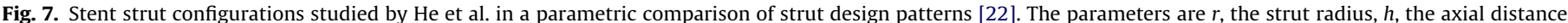
between the struts and $f$, the axial strut length. 
a
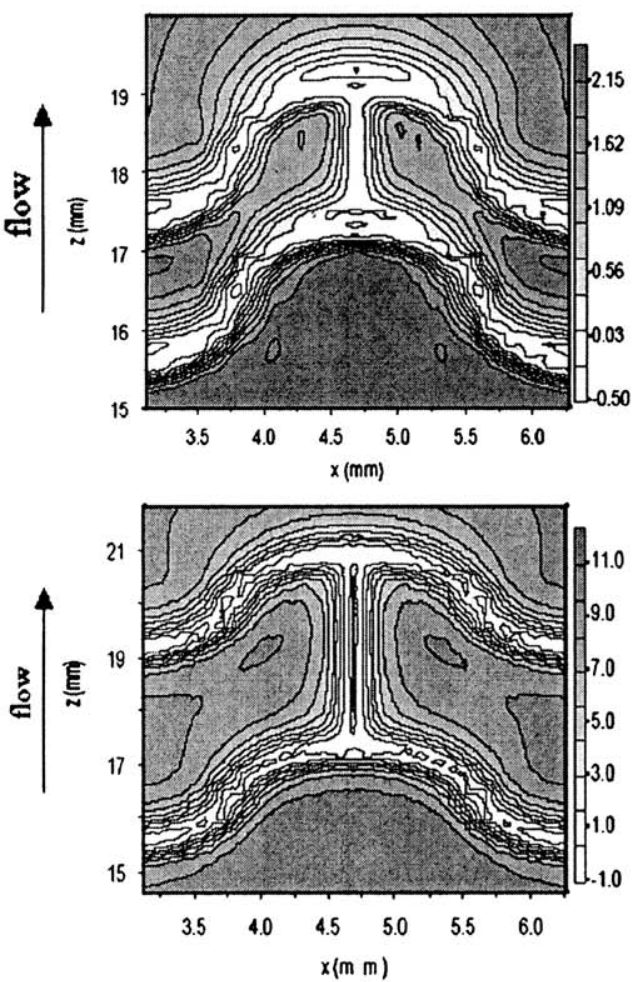

b

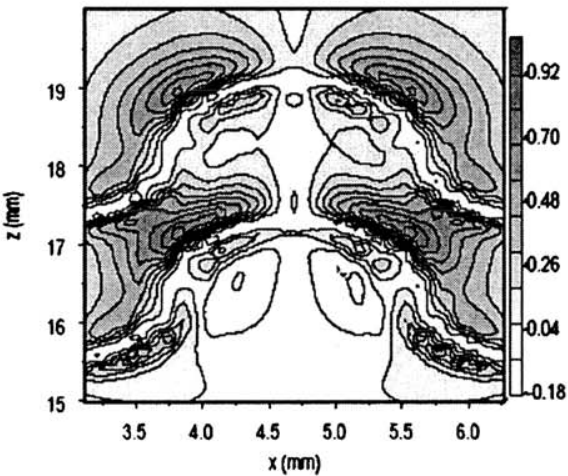

C
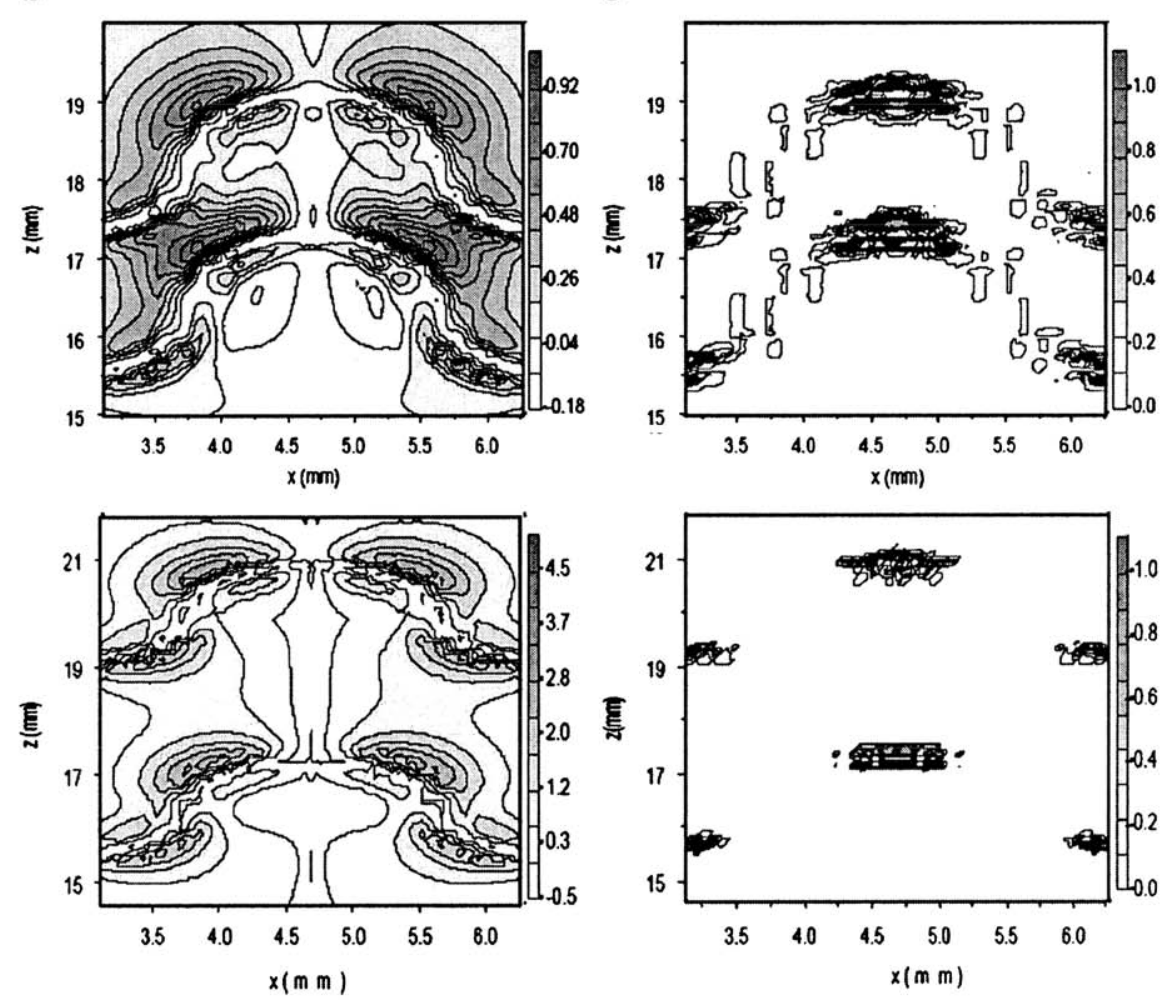

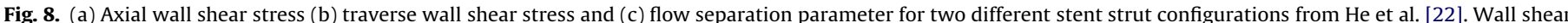
stress values given in Dynes $/ \mathrm{cm}^{2}$, where $1 \mathrm{~N} / \mathrm{m}^{2}=10$ Dynes $/ \mathrm{cm}^{2}$.

Table 3

Indices of mean time-averaged wall shear stress and normalised stented area with wall shear stress below $0.5 \mathrm{~N} / \mathrm{m}^{2}$, wall shear stress gradient above $200 \mathrm{~N} / \mathrm{m}^{3}$ and flow separation parameter above 0.5 for greater than $50 \%$ of the cardiac cycle, $T$, for the Wallstent, Bx-Velocity, Aurora and NIR stents from Duraiswamy et al. [41].

\begin{tabular}{lrcrr}
\hline Stent & Wallstent & Bx-Velocity & Aurora & NIR \\
\hline TAWSS $\left(\mathrm{N} / \mathrm{m}^{2}\right)$ & 0.29 & 0.58 & 0.50 & 0.53 \\
WSS $<0.5 \mathrm{~N} / \mathrm{m}^{2}(>50 \% \mathrm{~T})(\%)$ & 90.46 & 59.30 & 57.10 & 58.70 \\
WSSG $>200 \mathrm{~N} / \mathrm{m}^{3}(>50 \% \mathrm{~T})(\%)$ & 100.00 & 75.00 & 82.80 & 87.90 \\
FSP $>0.5(>50 \% \mathrm{~T})(\%)$ & 0.60 & 20.40 & 5.50 & 5.20 \\
\hline
\end{tabular}

below. The TAWSS was lowest for the Wallstent with a value of $0.29 \mathrm{~N} / \mathrm{m}^{2}$ and similar for the other three with values of $0.50,0.53$ and $0.58 \mathrm{~N} / \mathrm{m}^{2}$ for the Aurora, NIR and Bx-Velocity stents respectively. The Wallstent had over $90 \%$ and $100 \%$ of its stented area with WSS $<0.5 \mathrm{~N} / \mathrm{m}^{2}$ and WSSG $>200 \mathrm{~N} / \mathrm{m}^{3}$ respectively for over $50 \%$ of the cardiac cycle. These are significantly poorer haemodynamic characteristics produced by the Wallstent compared to the other three. This was reflected by the in vivo stent performance as angiographic restenosis rates at 6-month follow-up were $26 \%$ and $46 \%$ for the NIR and Wallstent respectively [42]. Another significant finding from this study was the percentage stented area with FSP $>0.5$ for over $50 \%$ of the cardiac cycle. The Bx-Velocity stent had $20.4 \%$ which is relatively high compared to $5.5 \%, 5.2 \%$ and $0.6 \%$ for the Aurora, NIR and Wallstent stents respectively. This finding is explained by a coinciding in vitro/CFD study [43] detailed below.

The in vitro model of a repeating unit of the Wallstent, BxVelocity and Aurora stents from Duraiswamy [43] examined platelet deposition inside the stent unit. CFD was also used to examine the streamlines of the flow in the near wall region of the strut unit. The CFD methodology was the same as that in the

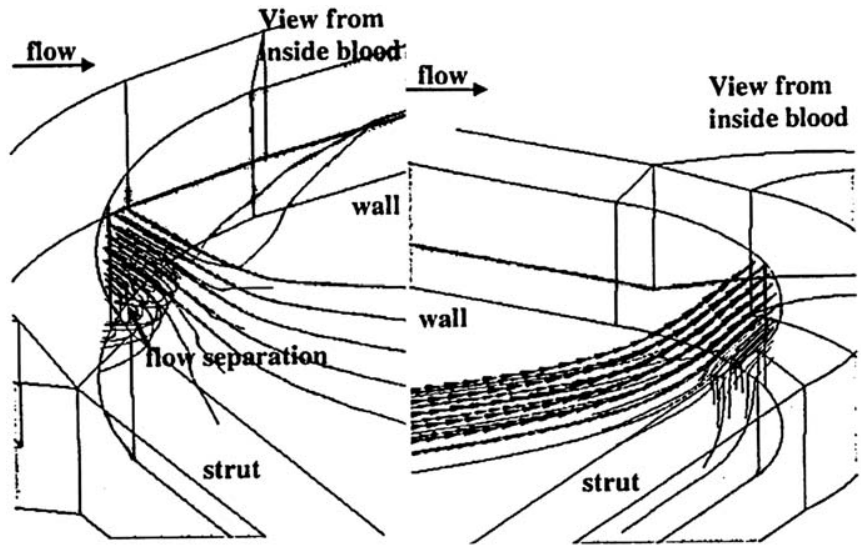

Fig. 9. Flow separation distal to strut $\mathrm{P}$ and proximal to strut $\mathrm{D}$ with the $\mathrm{Bx}$ Velocity stent from Duraiswamy et al. [43].

previous CFD study of the WSS [41]. The main finding was that there were regions of constant flow separation distal and proximal to the struts $\mathrm{P}$ (proximal) and $\mathrm{D}$ (distal) respectively as shown in Fig. 9. These constant separation regions exhibited very low platelet deposition. The platelet deposition was highest downstream of the recirculation regions due to convection towards the wall as shown in Fig. 10. The streamlines also revealed complex helically recirculating flow patterns near the Sshaped axial connector of the Bx-Velocity stent (not shown here). This would explain the high FSP values associated with this stent in the previous CFD study [41].

Balossino et al. [44] have also compared four commercially available stent designs. In the paper, stents $\mathrm{A}, \mathrm{B}, \mathrm{C}$ and $\mathrm{D}$ correspond to the Bx-Velocity stent, Jostent Flex (JOMED AB, 


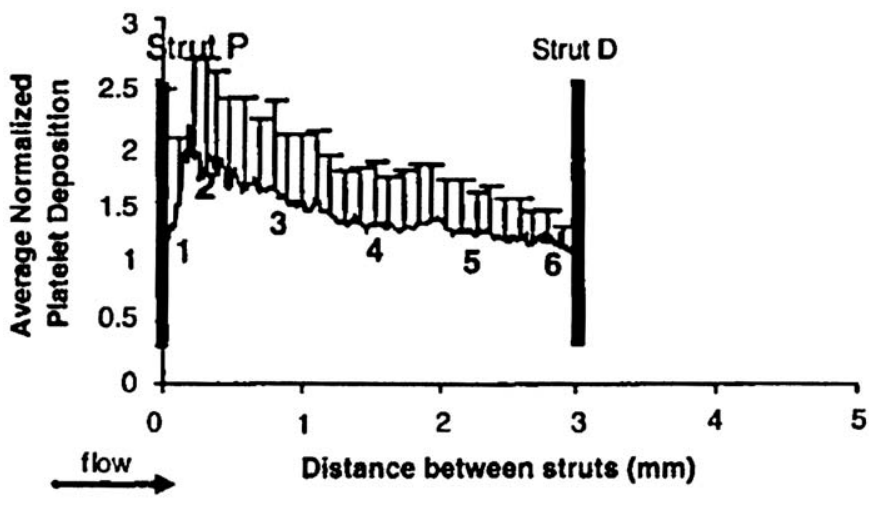

Fig. 10. Platelet deposition between the stent struts of the Bx-Velocity stent from Duraiswamy et al. [43]. There is low platelet deposition distal to strut $\mathrm{P}$ and proximal to strut D where the flow separation occurs as shown in Fig. 9.

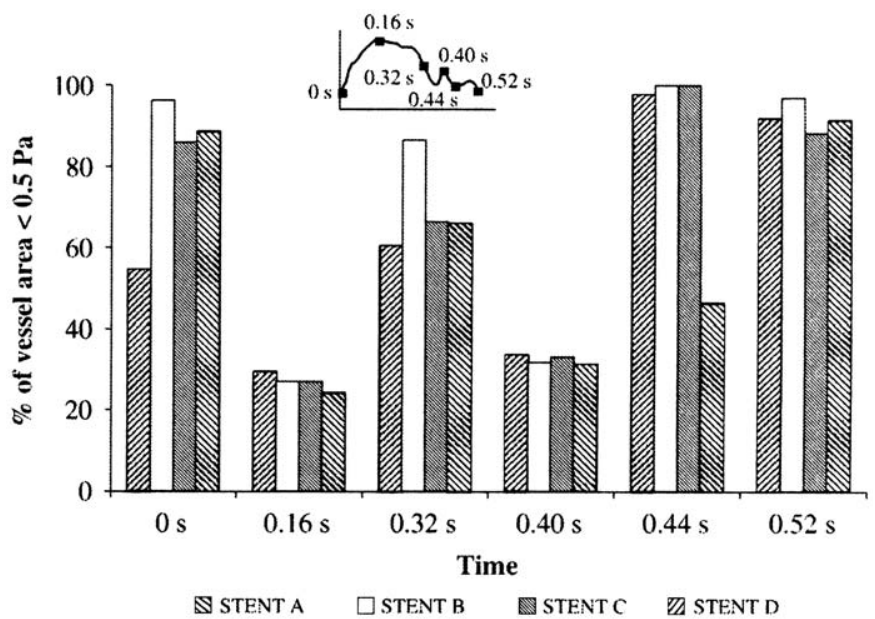

Fig. 11. Histograms of the percentage vascular wall surface with wall shear stress values lower than $0.5 \mathrm{~N} / \mathrm{m}^{2}$ for the four stents at six time intervals from Balossino et al. [44]. Stents A, B, C and D correspond to the Bx-Velocity, Jostent Flex, Sorin Carbostent and Palmaz-Schatz stents respectively.

Helsingborg, Sweden), Sorin Carbostent (Sorin Biomedica, Saluggia, Italy) and the Palmaz-Schatz (Johnson and Johnson Interventional system, NJ, USA) respectively. They used finite element analysis to model the expansion of a single unit of each stent into separate arteries containing idealised plaques. The rigid shape of deformed stent, artery and plaque were then used to define the boundaries of the CFD domain. A canine blood flow velocity waveform [32] was applied at the inlet. The most significant result was that there was not significant variation in the results between the different stent models as shown in Fig. 11. The timeaveraged value of percentage of vessel area below $0.5 \mathrm{~N} / \mathrm{m}^{2}$ was $57.8 \%$ for stent A and $57.3 \%$ for stent B. They also demonstrated that the highest WSS exists on the stent struts throughout the cardiac cycle. Thicker struts were also shown to slightly decrease the area subjected to low WSS $<0.5 \mathrm{~N} / \mathrm{m}^{2}$ over the cardiac cycle. A disadvantage of this study was the only parameters used to differentiate between the stents were low and maximum WSS.

\section{Conclusions/recommendations}

The current work reviews the most important of the recent CFD modelling of time-dependant blood flow in stented coronary arteries. The primary focus of this computational modelling is to identify and eliminate the different stimuli of restenosis in the stented artery. Following stent implantation, the largest contributor to restenosis is the growth of new tissue, termed $\mathrm{NH}$, inside the stented segment. Fluid flow variables, obtained from CFD can be used as indicators to predict sites where the $\mathrm{NH}$ will be excessive in the stented artery. The correlation of the indicators with sites of in vivo evidence of tissue growth, leads to recommendations for improved stent design and the stenting procedure.

All computational models are subject to some degree of deviation from the actual physics of the event that they simulate. This is especially true of CFD models of stented coronary arteries, as every stented coronary artery in the world is distinctly unique. However, there are certain aspects of stented coronary arteries that remain the same for the majority of cases. Future investigators must endeavour to include these aspects in their models and not neglect them due to simplification. From a geometric standpoint, stent design $[28,45]$, arterial tissue prolapse $[32,45]$, vessel curvature [35,37], and stent deployment ratio [45,46] all have a huge impact on stent haemodynamics and tissue growth indicators. From a modelling standpoint, the assumption of laminar, Newtonian flow, the assumption of rigid walls, incorrect velocity and pressure boundary conditions and use of geometric symmetry may lead to substantial error in the CFD results.

The WSS is an extremely useful indicator function, as sites of low WSS are frequently correlated with sites of increased $\mathrm{NH}$ $[24,27,37,47]$. The WSSG is also useful as sites of high WSSG have also been correlated with sites of increased $\mathrm{NH}[12,13,37,48]$. Sites of high WSSG generally occur in locations where the WSS is also reasonably high, so without this variable these sites with increased risk for $\mathrm{NH}$ would be neglected.

Sites of high OSI have been shown to be more prone to atherosclerotic lesion development in carotid arteries [15] and also experience increased endothelial cell permeability [17], although to the author's knowledge there has been no correlation between high OSI and in-stent NH. It does however seem likely regions of high OSI would be more at risk of tissue growth, but if the WSS involved is of low magnitude then the WSS variable would have already identified this region. Therefore, the OSI is useful only to identify areas of oscillating shear of high magnitude $\left(>0.5 \mathrm{~N} / \mathrm{m}^{2},<-0.5 \mathrm{~N} / \mathrm{m}^{2}\right.$ ) when used in conjunction with the WSS variable. The MOSI is a superior variable to the OSI because the directional value of the WSS is included in the integration providing information on the flow direction over the cardiac cycle.

The FSP returns the fraction of the cardiac cycle that the WSS is reversed from the direction of the mainstream flow. The premise of this variable is that blood-borne particles accumulate in areas of recirculation where the FSP is high and hence, encourage $\mathrm{NH}$ [22]. The work of Frank et al. [40] and Duraiswamy et al. [43] which shows the lowest platelet deposition with the strut spacing that creates the highest FSP suggests this variable is not a useful indicator for $\mathrm{NH}$ from a platelet deposition perspective. However, the separated flow is likely to adversely affect the function of the endothelial cells which leads to $\mathrm{NH}$.

Finally, the wall shear stress angle gradient (WSSAG) proposed by Longest et al. has yet to be examined in a model of a stented artery and could provide a useful tool to identify areas of increased endothelial cell permeability [49].

A number of stenting procedural and design recommendations can be drawn from the reviewed body of work. Stent flexibility in curved vessels has been shown to be important to reduce stress in the artery wall at the inlet and outlet of the stented region [36], and also to maintain greater uniformity in the profile of the blood flow [37]. Stents that tend to straighten the artery result in large alterations in the spatial distribution of WSS in the stented region [37]. A flexible stent which conforms to the natural curvature of the artery is therefore a more desirable stent. 
When the stent strut spacing is adequate, WSS of at least $0.5 \mathrm{~N} /$ $\mathrm{m}^{2}$ should be restored on the endothelial cells in the inter-strut space to ensure the minimal amount of endothelial dysfunction. Frank et al. have shown that the flow reattachment required to produce this WSS value may be at the price of increased platelet deposition [40]. However, without a functioning layer of endothelial cells there will almost certainly be extensive $\mathrm{NH}$. It is therefore recommended in line with Berry et al. [21]. and Frank et al. [40] that the strut spacing be six or more times the height of the strut. However, increasing the strut spacing will increase the tissue prolapse between the struts and it has been demonstrated that this markedly increases the WSSG acting on the prolapse tissue $[32,45]$.

The future CFD investigators of stented arteries should strive to create models that are as physiologically realistic as possible, carefully taking into account all the aforementioned geometric and modelling limitations commonly encountered. The focus of these models is likely to shift to identifying transport and delivery of tissue growth-inhibiting drugs from the stent to the vessel wall. However, investigators should not lose sight of the important indicators for and locations of in-stent $\mathrm{NH}$ presented in this paper. Effort should be made to deliver the drug to the higher risk locations such as the proximal region and along the myocardial surface. Finally, future CFD analyses should seek to answer specific questions that can be translated directly into recommendations for stent designers and clinicians.

\section{Conflict of interest statement}

None declared.

\section{References}

[1] S. Allender, P. Scarborough, V. Peto, M. Raymer, J. Leal, R. Luengo-Fernandez, A. Gray, European cardiovascular disease statistics: European Heart Network, 2008.

[2] A. Grüntzig, Transluminal dialation of coronary-artery stenosis, The Lancet 311 (1978) 263.

[3] K. Detre, R. Holubkov, S. Kelsey, et al., Percutaneous tranluminal coronary angioplasty in 1985-1986 and 1977-1981. The national heart lung and blood registry, N. Engl. J. Med. 318 (1988) 265-270.

[4] A.R. Gruentzig, S.B. King, W. Schlumpf, Long-term follow-up after percutaneous transluminal coronary angioplasty. The early Zurich experience, N. Engl. J. Med. 316 (1987) 1127-1132.

[5] J.K. Kahn, G.O. Hartzler, Frequency and causes of failure with contempory balloon angioplasty and implications for new technologies, Am. J. Cardiol. 66 (1990) 858-860.

[6] D.R.J. Holmes, R.E. Vlietstra, H.C. Smith, G.W. Vetrovec, et al., Restenosis after percutaneous transluminal coronary angioplasty (PTCA): a report from the PTCA Registry of the National Heart, Lung, and Blood Institute, Am. J. Cardiol. 53 (1984) 77C-81C.

[7] J.P. Carrozza Jr., R.E. Kuntz, M.J. Levine, R.M. Pomerantz, R.F. Fishman, M. Mansour, C.M. Gibson, C.C. Senerchia, D.J. Diver, R.D. Safian, Angiographic and clinical outcome of intracoronary stenting: immediate and long-term results from a large single-center experience, J. Am. Coll. Cardiol. 20 (1992) 328-337.

[8] E. Van Belle, C. Bauters, E. Hubert, J.-C. Bodart, K. Abolmaali, T. Meurice, E.P. McFadden, J.-M. Lablanche, M.E. Bertrand, Restenosis rates in diabetic patients: a comparison of coronary stenting and balloon angioplasty in native coronary vessels, Circulation 96 (1997) 1454-1460.

[9] C. Lally, F. Dolan, P.J. Prendergast, Cardiovascular stent design and vessel stresses: a finite element analysis, J. Biomech. 38 (2005) 1574-1581.

[10] A.M. Malek, S.L. Alper, S. Izumo, Hemodynamic shear stress and its role in atherosclerosis, J. Am. Med. Assoc. 282 (1999) 2035-2042.

[11] J.F.J. LaDisa, L.E. Olson, R.C. Molthen, D.A. Hettrick, P.F. Pratt, M.D. Hardel, J.R. Kersten, D.C. Warltier, P.S. Pagel, Alterations in wall shear stress predict sites of neointimal hyperplasia after stent implantation in rabbit iliac arteries, Am. J. Physiol. Heart Circ. Physiol. 288 (2005) H2465-H2475.

[12] S.M. Kute, D.A. Vorp, The effect of proximal artery flow on the hemodynamics at the distal anastomosis of a vascular bypass graft: computational study, J. Biomech. Eng. 123 (2001) 277-283.

[13] M. Ojha, Spatial and temporal variations of wall shear stress within an endto-side arterial anastomosis model, J. Biomech. 26 (1993) 1377-1388.
[14] N. DePaola, M.A.J. Gimbrone, P.F. Davies, C.F. Dewey, Vascular endothelium responds to fluid shear stress gradients, Arterioscler. Thromb. 12 (1992) $1254-1257$.

[15] D.N. Ku, D.P. Giddens, C.K. Zarins, S. Glagov, Pulsatile flow and atherosclerosis in the human carotid bifurcation. Positive correlation between plaque location and low oscillating shear stress, Arterioscler. Thromb. Vasc. Biol. 5 (1985) 293-302.

[16] C.K. Zarins, D.P. Giddens, B.K. Bharadvaj, V.S. Sottiurai, R.F. Mabon, S. Glagov, Carotid bifurcation atherosclerosis. Quantitative correlation of plaque localization with flow velocity profiles and wall shear stress, Circ. Res. 53 (1983) 502-514.

[17] H.A. Himburg, D.M. Grzybowski, A.L. Hazel, J.A. LaMack, X.-M. Li, M.H Friedman, Spatial comparison between wall shear stress measures and porcine arterial endothelial permeability, Am. J. Physiol. Heart Circ. Physiol. 286 (2004) H1916-H1922.

[18] A. Malek, S. Izumo, Physiological fluid shear stress causes downregulation of endothelin-1 mRNA in bovine aortic endothelium, Am. J. Physiol. Cell Physiol. 263 (1992) C389-C396.

[19] W.W. Nichols, M.F. O'Rourke, in: McDonald's Blood Flow in Arteries, Hodder Arnold, London, 2005, pp. 326-327.

[20] D. Rajamohan, R.K. Banerjee, L.H. Back, A.A. Ibrahim, M.A. Jog, Developing pulsatile flow in a deployed coronary stent, J. Biomech. Eng. 128 (2006) 347-359.

[21] J. Berry, A. Santamarina, J. Moore, S. Roychowdhury, W. Routh, Experimental and computational flow evaluation of coronary stents, Ann. Biomed. Eng. 28 (2000) 386-398.

[22] Y. He, N. Duraiswamy, A.O. Frank, J.E. Moore Jr., Blood flow in stented arteries: a parametric comparison of strut design patterns in three dimensions, J. Biomech. Eng. 127 (2005) 637-647.

[23] A. Kastrati, J. Mehilli, J. Dirschinger, J. Pache, K. Ulm, H. Schuhlen, M. Seyfarth C. Schmitt, R. Blasini, F.J. Neumann, A. Schomig, Restenosis after coronary placement of various stent types, Am. J. Cardiol. 87 (2001) 34-39.

[24] J.M. Garasic, E.R. Edelman, J.C. Squire, P. Seifert, M.S. Williams, C. Rogers, Stent and artery geometry determine intimal thickening independent of arterial injury, Circulation 101 (2000) 812-818.

[25] R.D. Gaston, S.M. Gary, D.P. Augusto, M.K. Kenneth, F.S. Lowell, J.P. Jeffrey, S.C. Wong, B.L. Martin, Small stent size and intimal hyperplasia contribute to restenosis: a volumetric intravascular ultrasound analysis, J. Am. Coll. Cardiol. 26 (1995) 720-724

[26] R. Mehran, G. Dangas, A.S. Abizaid, G.S. Mintz, A.J. Lansky, L.F. Satler, A.D. Pichard, K.M. Kent, G.W. Stone, M.B. Leon, Angiographic Patterns of in-stent restenosis: classification and implications for long-term outcome, Circulation 100 (1999) 1872-1878.

[27] J.J. Wentzel, R. Krams, J.C.H. Schuurbiers, J.A. Oomen, J. Kloet, W.J. van der Giessen, P.W. Serruys, C.J. Slager, Relationship between neointimal thickness and shear stress after wallstent implantation in human coronary arteries, Circulation 103 (2001) 1740-1745.

[28] J. LaDisa, L. Olson, D. Hettrick, D. Warltier, J. Kersten, P. Pagel, Axial stent strut angle influences wall shear stress after stent implantation: analysis using 3D computational fluid dynamics models of stent foreshortening, BioMed. Eng. OnLine 4 (2005) 59.

[29] R.K. Banerjee, S.B. Devarakonda, D. Rajamohan, L.H. Back, Developed pulsatile flow in a deployed coronary stent, Biorheology 44 (2007) 91-102.

[30] I. Faik, et al., Time-dependent 3D simulations of the hemodynamics in a stented coronary artery, Biomed. Mater. 2 (2007) S28.

[31] J.F. LaDisa, I. Guler, L.E. Olson, D.A. Hettrick, J.R. Kersten, D.C. Warltier, P.S Pagel, Three-dimensional computational fluid dynamics modeling of alterations in coronary wall shear stress produced by stent implantation, Ann. Biomed. Eng. 31 (2003) 972-980.

[32] J.F. LaDisa Jr., L.E. Olson, I. Guler, D.A. Hettrick, J.R. Kersten, D.C. Warltier, P.S Pagel, Circumferential vascular deformation after stent implantation alters wall shear stress evaluated with time-dependent 3D computational fluid dynamics models, J. Appl. Physiol. 98 (2005) 947-957.

[33] O. Smedby, J. Johansson, J. Molgaard, A.G. Olsson, G. Walldius, U. Erikson, Predilection of atherosclerosis for the inner curvature in the femoral artery: a digitized angiography study, Arterioscler. Thromb. Vasc. Biol. 15 (1995) 912-917.

[34] M. Prosi, K. Perktold, Z. Ding, M.H. Friedman, Influence of curvature dynamics on pulsatile coronary artery flow in a realistic bifurcation model, J. Biomech. 37 (2004) 1767-1775.

[35] T. Seo, L.G. Schachter, A.I. Barakat, Computational study of fluid mechanical disturbance induced by endovascular stents, Ann. Biomed. Eng. 33 (2005) 444-456.

[36] J.J. Wentzel, D.M. Whelan, W.J. van der Giessen, H.M. van Beusekom, I. Andhyiswara, P.W. Serruys, C.J. Slager, R. Krams, Coronary stent implantation changes 3-D vessel geometry and 3-D shear stress distribution, J. Biomech. 33 (2000) 1287-1295.

[37] J. LaDisa, L. Olson, H. Douglas, D. Warltier, J. Kersten, P. Pagel, Alterations in regional vascular geometry produced by theoretical stent implantation influence distributions of wall shear stress: analysis of a curved coronary artery using 3D computational fluid dynamics modeling, BioMed. Eng. OnLine 5 (2006) 40 .

[38] H.Y. Chen, J. Hermiller, A.K. Sinha, M. Sturek, L. Zhu, G.S. Kassab, Effects of stent sizing on endothelial and vessel wall stress: potential mechanisms for in-stent restenosis, J. Appl. Physiol. 106 (2009) 1686-1691. 
[39] A.J. Lansky, G.S. Roubin, C.D. O’Shaughnessy, P.B. Moore, L.S. Dean, A.E. Raizner, R.D. Safian, J.P. Zidar, J.L. Kerr, J.J. Popma, R. Mehran, R.E. Kuntz, M.B. Leon, Randomized comparison of GR-II stent and palmaz-schatz stent for elective treatment of coronary stenoses, Circulation 102 (2000) 1364-1368.

[40] A.O. Frank, P.W. Walsh, J.E.J. Moore, Computational fluid dynamics and stent design, Artif. Organs 26 (2002) 614-621.

[41] N. Duraiswamy, R.T. Schoephoerster, J. James E. Moore, Comparison of nearwall hemodynamic parameters in stented artery models, J. Biomech. Eng. 131 (2009) 061006 (Unbound).

[42] T. Nageh, A.J. de Belder, M.R. Thomas, I.L. Williams, R.J. Wainwright, A randomised trial of endoluminal reconstruction comparing the NIR stent and Wallstent in angioplasty of long segment coronary disease: results of the RENEWAL studt, Am. Heart J. 141 (2001) 971-976.

[43] N. Duraiswamy, J.M. Cesar, R.T. Schoephoerster, J.E. Moore Jr., Effects of stent geometry on local flow dynamics and resulting platelet deposition in an in vitro model, Biorheology 45 (2008) 547-561.

[44] R. Balossino, F. Gervaso, F. Migliavacca, G. Dubini, Effects of different stent designs on local hemodynamics in stented arteries, J. Biomech. 41 (2008) 1053-1061.
[45] J. Murphy, F. Boyle, Assessment of the effects of increasing levels of physiological realism in the computational fluid dynamics analyses of implanted coronary stents, in: Proceedings of the Engineering in Medicine and Biology Society, 30th Annual International Conference of the IEEE (2008).

[46] J.F.J. LaDisa, L.E. Olson, I. Guler, D.A. Hettrick, S.H. Audi, J.R. Kersten, D.C. Warltier, P.S. Pagel, Stent design properties and deployment ratio influence indexes of wall shear stress: a three-dimensional computational fluid dynamics investigation within a normal artery, J. Appl. Physiol. 97 (2004) 424-430.

[47] M.H. Friedman, G.M. Hutchins, C.B. Bargeron, O.J. Deters, F.F. Mark, Correlation between intimal thickness and fluid shear in human arteries, Atherosclerosis 39 (1981) 425-436.

[48] M. Lei, C. Kleinstreuer, G.A. Truskey, A focal stress gradient-dependent mass transfer mechanism for atherogenesis in branching arteries, Med. Eng. Phys. 18 (1996) 326-332.

[49] P.W. Longest, C. Kleinstreuer, Computational haemodynamics analysis and comparison study of arterio-venous grafts, J. Med. Eng. Technol 24 (2000) 102-110. 